\title{
Molecular insights into plant cell proliferation disturbance by Agrobacterium protein 6b
}

\author{
Meimei Wang, ${ }^{1,2}$ Takashi Soyano, ${ }^{3}$ Satoru Machida, ${ }^{1,2}$ Jun-Yi Yang, ${ }^{3}$ Choonkyun Jung, ${ }^{3}$ \\ Nam-Hai Chua, ${ }^{3}$ and Y. Adam Yuan ${ }^{1,2,4}$ \\ ${ }^{1}$ Department of Biological Sciences, National University of Singapore, Singapore 117543, Singapore; ${ }^{2}$ Temasek Life Sciences \\ Laboratory, National University of Singapore, Singapore 117604, Singapore; ${ }^{3}$ Laboratory of Plant Molecular Biology, The \\ Rockefeller University, New York, New York 10065, USA
}

The Agrobacterium Ti plasmid (T-DNA) $6 b$ proteins interact with many different host proteins implicated in plant cell proliferation. Here, we show that Arabidopsis plants overexpressing 6b display microRNA (miRNA) deficiency by directly targeting SERRATE and AGO1 via a specific loop fragment (residues 40-55). In addition, we report the crystal structures of Agrobacterium tumefaciens AK6b at $2.1 \AA$, Agrobacterium vitis AB6b at $1.65 \AA$, and Arabidopsis ADP ribosylation factor (ARF) at 1.8 $⿱$. The $6 \mathrm{~b}$ structure adopts an ADP-ribosylating toxin fold closely related to cholera toxin. In vitro ADP ribosylation analysis demonstrates that $6 \mathrm{~b}$ represents a new toxin family, with Tyr 66, Thr 93, and Tyr 153 as the ADP ribosylation catalytic residues in the presence of Arabidopsis ARF and GTP. Our work provides molecular insights, suggesting that $6 \mathrm{~b}$ regulates plant cell growth by the disturbance of the miRNA pathway through its ADP ribosylation activity.

[Keywords: ADP ribosylation toxin; Agrobacterium protein 6b; crystal structure; miRNA machinery; miRNA phenotype] Supplemental material is available for this article.

Received August 23, 2010; revised version accepted November 2, 2010.

Agrobacterium tumefaciens cells that harbor Ti plasmid (T-DNA) induce crown gall tumors on dicotyledonous plants. Among the T-DNA-encoded proteins, $6 \mathrm{~b}$ appears to play a role in the expression of plant genes related to cell proliferation and the modification of crown gall morphology, although the $6 \mathrm{~b}$ protein itself is not required for the formation of crown galls (Garfinkel et al. 1981; Tinland et al. 1992).

The $6 b$ genes have remarkable and unique effects on plant growth. They induce tumors on stems in a limited number of plant species, including Nicotiana glauca (Hooykaas et al. 1988; Tinland et al. 1989; Kitakura et al. 2002), grapevine (Huss et al. 1990), and Nicotiana rustica (Garfinkel et al. 1981; Paulus et al. 1991); increase wound-induced division of cells in N. rustica (Tinland et al. 1992); promote iaa- and ipt-induced cell division (Hooykaas et al. 1988; Tinland et al. 1989); and enhance tumor formation or increase the size of crown galls induced on $N$. rustica through the action of the auxin genes and the cytokinin gene (Tinland et al. 1989). Expression of $6 b$ genes also elicits morphological and anatomical changes in tobacco plants, and modifies

${ }^{4}$ Corresponding author.

E-MAIL adam@tll.org.sg; FAX 65-68727007.

Article published online ahead of print. Article and publication date are online at http://www.genesdev.org/cgi/doi/10.1101/gad.1985511. cotyledons, flowers, petioles, stems, and roots (Tinland et al. 1990, 1992; Helfer et al. 2003; Gremillon et al. 2004). Transgenic $6 \mathrm{~b}$ tobacco plants develop enations, catacorollas, tubular leaves, fragmented leaf primordia, hyponastic petioles, and epinastic leaf veins (Clément et al. 2006).

The predicted amino acid sequence of $6 \mathrm{~b}$ is distantly related to the RolB family proteins, whose expression also results in aberrant growth and abnormal morphology of both roots and shoots (Spena et al. 1987; Levesque et al. 1988; Stieger et al. 2004). Protein $6 \mathrm{~b}$ localizes to the nucleus and was reported to bind to several nuclear proteins - such as NtSIP1 (Nicotiana tabacum Six-b-interacting protein 1) (Kitakura et al. 2002), NtSIP2 (Kitakura et al. 2008), and histone H3 (Terakura et al. 2007)—and affects the expression of various plant genes in transgenic Arabidopsis. Transgenic Arabidopsis plants expressing the $A K 6 b$ gene display leaf abnormality at early developmental stages, such as upward curling and serration of leaves, protrusion on the abaxial side of leaves, altered flower structure, and callus formation on hormone-free medium.

Much effort has been expended to elucidate $6 \mathrm{~b}$ functions at the cellular and molecular levels. So far, different hypotheses have been proposed to explain the effects of $6 b$ on the growth of plant cells. The $6 b$ gene could possess auxin-like and cytokinin-like activity by modulating auxin or cytokinin receptors, and promote activity of genes involved in auxin and cytokinin biosynthesis 
(Wabiko and Minemura 1996; Clément et al. 2006). 6b might induce plants to synthesize a phloem-mobile growth factor (enation factor) (Helfer et al. 2003). In addition, the $6 b$ gene has also been proposed to modulate the metabolism of phenolic compounds (Gális et al. 2002, 2004; Kakiuchi et al. 2006); induce changes in gene expression, resulting in phenylpropanoid changes (Kitakura et al. 2002; Terakura et al. 2006); modify osmotic controls required for normal and wound-induced cell expansion (Clément et al. 2006); and cause the absorption, retention, and abnormal accumulation of sugars (Clément et al. 2007).

Recent studies on $6 b$ further suggest that $6 b$ might affect chromatin status as a chromatin chaperon or affect the expression of class I KNOX,CUC, IAA, and cell cycle-related genes as a transcriptional regulator of plant cell proliferation in tobacco and Arabidopsis (Terakura et al. 2006, 2007)

Although much work has been done on $6 b$, the exact functional role of $6 \mathrm{~b}$ at the molecular level remains unknown owing to the lack of structural motif information obtained from $6 \mathrm{~b}$ sequences. To investigate the molecular mechanism of leaf abnormality elicited by $6 \mathrm{~b}$ overexpression in plants, we report here that Arabidopsis plants overexpressing $6 \mathrm{~b}$ display a microRNA (miRNA) deficiency phenotype. This phenotype can be attributed to the targeting of the miRNA pathway by targeting the miRNA processing machinery and slicing machinery by $6 \mathrm{~b}$. In addition, we also report high-resolution crystal structures of AK6b, AB6b, and Arabidopsis ADP ribosylation factor (ARF). Our data demonstrate that $6 \mathrm{~b}$ adopts an $\mathrm{ADP}$ ribotransferase fold quite close to that of cholera toxin and displays ADP ribosylation activity in the presence of Arabidopsis ARF and GTP. However, 6b has a completely different set of residues within the substrate-binding pocket for ADP ribosylation activity.

\section{Results}

$6 b$ interferes with miRNA pathways in Arabidopsis

Many plant viruses are known to encode proteins that suppress RNA silencing and interfere with the miRNA pathway (Zhang et al. 2006b; Baumberger et al. 2007; Bortolamiol et al. 2007). Since T-DNA can be considered a DNA virus, we speculated that the $6 \mathrm{~b}$ protein may also interfere with the miRNA pathway in Arabidopsis. Careful comparison of the morphological phenotypes of $35 S:: A K 6 b$ overexpression in plants with ago1-27 and se-1 mutant lines showed that these transgenic plants partially phenocopied these two miRNA-deficient mutants, which have strongly serrated leaves (Fig. 1A). This observation prompted us to investigate the expression levels of several miRNAs involved in leaf development, and their target mRNAs. Along with the severe morphological phenotype accompanying the overexpression of 35S::AK6b in Arabidopsis, miR162, miR164, and miR319 were significantly decreased, whereas miR165/166 was slightly decreased (Fig. 1B, left panel). On the other hand, the mRNA targets of these miRNAs accumulated to a high level, showing an inverse correlation with the low expres-
A

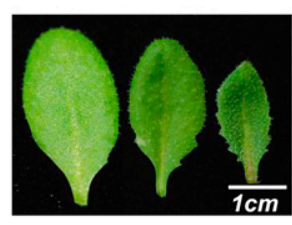

Col-O WT

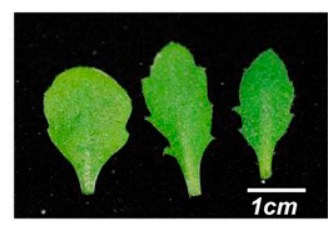

ago1-27

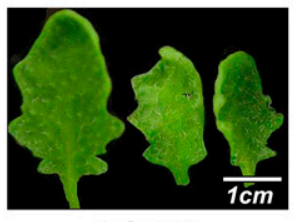

$35 S:: A K 6 b$

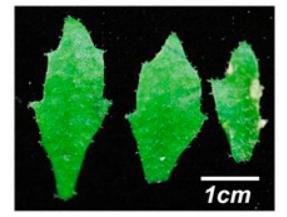

se-1

B
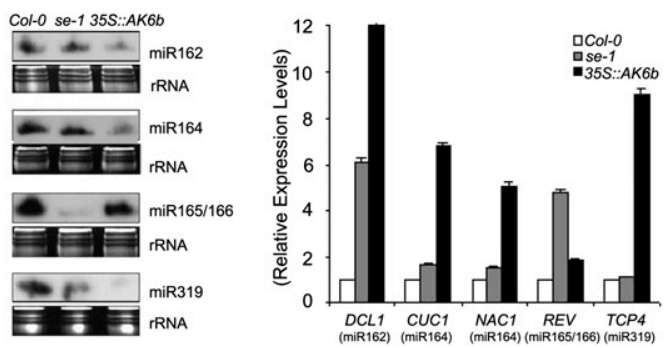

Figure 1. Expression of miRNA in $A K 6 b$ transgenic plants. $(A)$ Comparison of the morphological phenotype between $35 S:$ : $A K 6 b$, ago1-27, and se-1 plants. Photographs were taken for the second, third, and fourth true leaves of 4-wk-old seedlings. Bar, $1 \mathrm{~cm}$. (B) Accumulation of small RNAs and target mRNAs in wild-type (Col-0), se-1, and $35 S:: A K 6 b$ plants. Each lane contained $12 \mu \mathrm{g}$ of RNA. rRNAs were used as a loading control. For analysis of target mRNAs, quantifications of each cDNA sample were made in triplicate, and consistent results from at least two independent RNA samples were used.

sion level of the individual miRNAs (Fig. 1B, right panel). Notably, the molecular miRNA-deficient phenotypes of $35 S:: A K 6 b$ plants and the se-1 mutant only partially overlapped. For example, the expression level of miR319 was significantly decreased in $35 S:: A K 6 b$ plants instead of the se-1 mutant (Fig. 1B, left panel). In contrast, the expression level of miR165/166 was significantly decreased in the se-1 mutant instead of $35 S:: A K 6 b$ plants (Fig. 1B, left panel). Similarly, the accumulation of their target mRNAs-such as TCP4 (miR319 target) and REV (miR165/166 target)-in 35S::AK6b plants and the se1 mutant was inversely correlated to the individual miRNA expression level (Fig. 1B, right panel).

\section{$6 b$ targeting Arabidopsis AGO1 and Serrate (SE) in vitro and in vivo}

The partially overlapping miRNA deficiency phenotypes among the $35 S:: A K 6 b$ plants, se-1 mutant, and ago1-27 mutant prompted us to test the possible direct interactions between AK6b, SE, and AGO1. We performed in vitro pulldown assays using various purified protein fragments to examine whether the AK6b-AGO1 or AK6b-SE interaction was direct, and attempted to map the interaction domains. We systematically generated six truncated AGO1 
mutants from the $\mathrm{N}$ terminus $(\mathrm{NT})$ to the $\mathrm{C}$ terminus $(\mathrm{CT})$. In vitro pull-down assays showed that the AGO1-NT fragment (residues 185-371) was the primary interaction domain targeted by AK6b (Fig. 2A). This fragment corresponds to the entrance channel for the small RNA and its target mRNA (Fig. 2B). To investigate the direct interaction between $6 \mathrm{~b}$ and $\mathrm{SE}$, we generated two truncated SE fragments from the $\mathrm{N}$ terminus to the $\mathrm{C}$ terminus. The in vitro pull-down assay showed that both the SE-NT fragment (residues 194-240) and the SE-Mid fragment (residues 241-469) were targeted by AK6b (Fig. 2C,D). To investigate whether $6 \mathrm{~b}$ interacts with SE and AGO1 in vivo, we performed coimmunoprecipitation (co-IP) experiments using extracts prepared from $35 S:: A K 6 b$ plants. We found that the SE antibody indeed detected a band in the immunocomplex pulled down by the AK6b antibody (Fig. 2E, bottom middle panel). Similarly, we were able to coimmunoprecipitate endogenous AGO1 by the AK6b antibody from the extracts of $35 S:: A K 6 b$ plants (Fig. 2E, bottom panel). The specificity of the anti-AtAGO1 antibody is shown in Supplemental Figure S1.

\section{$6 b$ targeting Arabidopsis Histone $\mathrm{H} 3$ in vitro}

To confirm whether $6 \mathrm{~b}$ has a broad spectrum of targets beyond the miRNA machineries and interacts directly with Arabidopsis Histone H3, we performed an in vitro pull-down assay by immobilizing GST-AK6b or GST-AB6b on the GST beads and incubating His-SUMO-H3 with the bound GST-AK6b or GST-AB6b protein. As expected, both GST-AK6b and GST-AB6b were able to pull down HisSUMO-H3, whereas GST alone was not able to pull down His-SUMO-H3 (Supplemental Fig. S2, left panel).

\section{Overall crystal structures of $A K 6 b$ and $A B 6 b$}

To investigate the molecular mechanism of $6 \mathrm{~b}$ proteins on miRNA pathway disturbance, we successfully solved
A

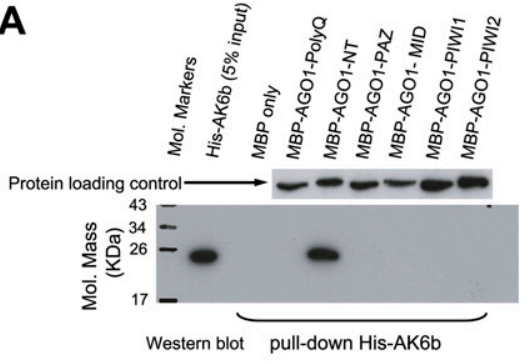

B

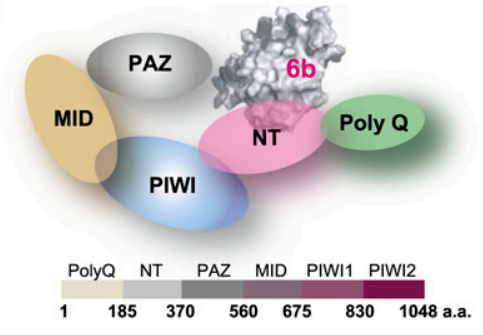

C
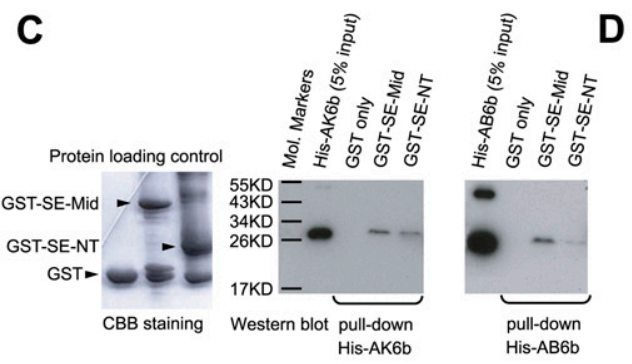

D

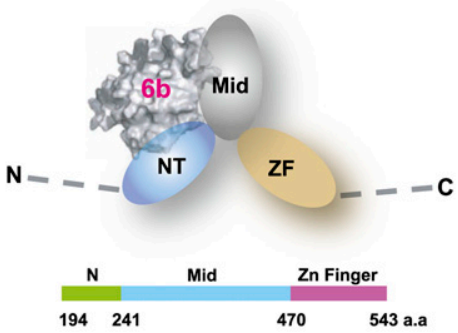

E

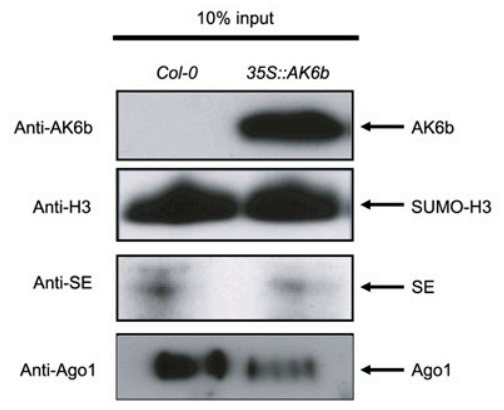

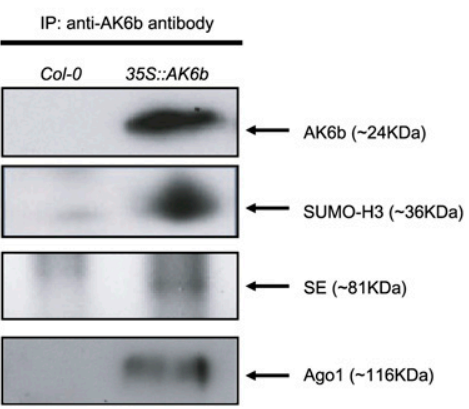

Figure 2. Interaction of AK6b, AGO1, and $\mathrm{SE}$ in vitro and in vivo. $(A)$ In vitro pulldown assays of His-AK6b interaction with MBP-AGO1 fragments. MBP-AGO1 fragments were immobilized on MBP beads and individually incubated with His-AK6b. Bound MBP-AGO1 fragments were retrieved, and the association of AK6b was monitored by Western blots using monoclonal antibodies against poly-His. (Top panel) Western blot analysis for the input of MBP-AGO1 fragments using a polyclonal antibody against a bacterial AGO-like homolog. (Bottom panel) The input and output of pulled-down His-AK6b analyzed by Western blot. (B) A cartoon showing binding of AK6b to one surface of the PAZcontaining module of AGO1, which harbors small RNA and its target mRNA-binding groove. Individual predicted domains are indicated on the cartoon. A schematic diagram showing the domain borders in Arabidopsis AGO1 is shown below. $(C)$ In vitro pull-down assays of SE fragments and $6 \mathrm{~b}$ proteins. GST-SE-Mid and GST-SE-NT were individually immobilized on GST beads, and His-AK6b or His-AB6b was incubated with bound SE fragments. (Left panel) Coomassie brilliant blue G250 staining of the input of SE fragments. (Middle and right panels) The input and output of His-AK6b or His-AB6b analyzed by Western blots with monoclonal antibodies against polyHis. (D) A cartoon showing binding of AK6b to one surface of the SE core domain, which probably harbors the protein-protein interaction platform. Individual predicted domains are indicated on the cartoon. A schematic diagram showing the domain borders in Arabidopsis SE core domain is shown below. (E) Interaction of AK6b and SE or AGO1 in Arabidopsis plants in vivo. Two-week-old seedlings expressing 35S::AK6b were treated overnight with $50 \mu \mathrm{M}$ MG132. Total protein extracts were immunoprecipitated (IP) with polyclonal antibody to AK6b. Western blots were analyzed with an AK6b polyclonal antibody to detect AK6b (top), with an H3 polyclonal antibody to detect Arabidopsis Histone H3 (second panel from the top), with SE polyclonal antibody to detect coimmunoprecipitated SE (third panel from the top), and with AGO1 monoclonal antibody to detect coimmunoprecipitated AGO1 (bottom panel). 
the high-resolution structures of $\mathrm{AK} 6 \mathrm{~b}$ and $\mathrm{AB} 6 \mathrm{~b}$. The crystal structure of the full-length A. tumefaciens AK6b at $2.1 \AA$ was solved by multiple anomalous dispersion (MAD) phasing, whereas Agrobacterium vitis AB6b at $1.65 \AA$ was determined by molecular replacement (using AK6b as the search model), with crystallographic statistics summarized in Table 1. AK6b and AB6b have very similar sequences and almost identical structures, except that AB6b harbors a little shorter repeating Glu residue loop in the middle. Therefore, hereafter we use the generic name $6 \mathrm{~b}$ to represent both the AK6b and AB6b proteins and the amino acid residue numbers from AK6b.

$6 \mathrm{~b}$ contains nine $\beta$ strands $(\beta 1-\beta 9)$, three regular $\alpha$ helices $(\alpha 1-\alpha 3)$, and two very short $\alpha$ helices $\left(\alpha 1^{\prime}-\alpha 2^{\prime}\right)$ (Fig. 3A), and possesses an $\alpha / \beta$ fold with five $\alpha$ helices packed against nine $\beta$ strands at one surface, with an overall dimension of $50 \AA \times 35 \AA \times 25 \AA$. The $6 \mathrm{~b}$ central module contains two perpendicular $\beta$ sheets $(\beta 1, \beta 2, \beta 5$, $\beta 8$, and $\beta$ 9 forming one group, and $\beta 3, \beta 4, \beta 6$, and $\beta 7$ forming another group) and one $\alpha$ helix $(\alpha 2)$ sitting on top of these two $\beta$ sheets, surrounded by several loops and two $\alpha$ helices $(\alpha 1$ and $\alpha 3)$ (Fig. 3B).

A well-ordered loop (residues 113-134)—including the two very short $\alpha$ helices $\left(\alpha 1^{\prime}\right.$ and $\left.\alpha 2^{\prime}\right)$-connecting $\alpha 3$ and $\beta 5$ forms a lid-like architecture covering the central structural module formed by the perpendicular $\beta$ sheets. Another well-ordered 17-amino-acid-long loop (residues 40-55) connecting $\alpha 1$ and $\beta 1$ extends from the central module of the structure. This loop participates in protein packing and may serve as a structural scaffold for proteinprotein interaction. The well-studied loop with repeating Glu residues (10 Glu residues for AK6b and six Glu residues for $\mathrm{AB} 6 \mathrm{~b}$ ) (Kitakura et al. 2002, 2008) is disordered in both AK6b and AB6b structures.

\section{Target-binding loop}

A comparison of the crystal packing of $\mathrm{AK} 6 \mathrm{~b}$ and $\mathrm{AB} 6 \mathrm{~b}$ revealed one conserved protein-protein interaction loop, which is unique to this protein family. In the $\mathrm{AK} 6 \mathrm{~b}$

Table 1. Data collection, phasing, and refinement statistics

\begin{tabular}{|c|c|c|c|c|c|}
\hline Data collection & & AK6b & & $\mathrm{AB} 6 \mathrm{~b}$ & AtARF \\
\hline Space group & & $\mathrm{P}_{2} 21$ & & $\mathrm{P} 2_{1} 2_{1} 2$ & $\mathrm{P} 2_{1} 2_{1} 2$ \\
\hline Molecules/ASU & & 3 & & 2 & 2 \\
\hline Data set & Peak & Inflection & Remote & Native & Native \\
\hline \multicolumn{6}{|l|}{ Cell dimensions } \\
\hline$a$ & & $80.458 \AA$ & & $79.366 \AA$ & $88.710 \AA$ \\
\hline$b$ & & $80.458 \AA$ & & $89.926 \AA$ & $89.977 \AA$ \\
\hline$c$ & & $245.708 \AA$ & & $59.583 \AA$ & $46.049 \AA$ \\
\hline Wavelength & $0.9790 \AA$ & $0.9794 \AA$ & $0.96 \AA$ & $1.1 \AA$ & $1.075 \AA$ \\
\hline Resolution $^{\mathrm{a}}$ & $\begin{array}{l}50 \sim 2.1 \AA \\
\quad(2.18 \sim 2.10 \AA)\end{array}$ & $\begin{array}{l}50 \sim 2.1 \AA \\
\quad(2.18 \sim 2.10 \AA)\end{array}$ & $\begin{array}{l}50 \sim 2.1 \AA \\
\quad(2.18 \sim 2.10 \AA)\end{array}$ & $\begin{array}{l}50 \sim 1.65 \AA \\
\quad(1.68 \sim 1.65 \AA)\end{array}$ & $\begin{array}{l}50 \sim 1.8 \AA \\
\quad(1.83 \sim 1.80 \AA)\end{array}$ \\
\hline $\mathrm{R}_{\text {sym }}$ & $7.4 \%(35.4 \%)$ & $7.4 \%(36.0 \%)$ & $8.2 \%(42.3 \%)$ & $7.3 \%(52.1 \%)$ & $5.0 \%(24.4 \%)$ \\
\hline$I / \sigma(I)$ & $30.3 / 2.8$ & $27.9 / 2.7$ & $22.8 / 1.3$ & $44.8 / 4.0$ & $55.9 / 11.4$ \\
\hline Completeness $^{\mathrm{a}}$ & $81.1 \%(32.9 \%)$ & $74.6 \%(21.8 \%)$ & $66.0 \%(12.9 \%)$ & $99.9 \%(99.6 \%)$ & $99.8 \%(100 \%)$ \\
\hline Redundancy & $9.7(4.4)$ & $9.7(3.7)$ & $7.7(7.3)$ & $13.9(10.5)$ & $14.1(14.5)$ \\
\hline $\begin{array}{l}\text { Initial figure of merit } \\
\text { Refinement }\end{array}$ & & 0.5 & & & \\
\hline Resolution range & $50 \sim 2.1 \AA$ & & & $50 \sim 1.65 \AA$ & $50 \sim 1.80 \AA$ \\
\hline $\begin{array}{l}\text { Number of } \\
\text { reflections }\end{array}$ & 43,896 & & & 49,396 & 33,083 \\
\hline $\mathrm{R}_{\text {work }} / \mathrm{R}_{\text {free }}$ & $20.2 \% / 23.7 \%$ & & & $17.8 \% / 20.6 \%$ & $24.1 \% / 19.9 \%$ \\
\hline \multicolumn{6}{|l|}{ Number of atoms } \\
\hline Protein & 4,588 & & & 3,046 & 2,665 \\
\hline Water & 258 & & & 342 & 290 \\
\hline GDP & & & & & 2 \\
\hline $\mathrm{Mg}^{2+}$ & & & & & 2 \\
\hline \multicolumn{6}{|l|}{ B factors } \\
\hline Protein & $39.8 \AA^{2}$ & & & $17.7 \AA^{2}$ & $27.6 \AA^{2}$ \\
\hline Water & $38.7 \AA^{2}$ & & & $34.2 \AA^{2}$ & $32.9 \AA^{2}$ \\
\hline GDP & & & & & $18.4 \AA^{2}$ \\
\hline $\mathrm{Mg}^{2+}$ & & & & & $16.4 \AA^{2}$ \\
\hline \multicolumn{6}{|l|}{$\begin{array}{l}\text { Root-mean-square } \\
\text { deviations }\end{array}$} \\
\hline Bond lengths & $0.010 \AA$ & & & $0.009 \AA$ & $0.015 \AA$ \\
\hline Bond angles & $1.18^{\circ}$ & & & $1.15^{\circ}$ & $1.50^{\circ}$ \\
\hline $\begin{array}{l}\text { Percent favored } \\
\text { (disallowed) in } \\
\text { Ramachandran plot }\end{array}$ & $90.3 \%(0 \%)$ & & & $92.4 \%(0 \%)$ & $93.7 \%(0 \%)$ \\
\hline
\end{tabular}

${ }^{\mathrm{a}}$ Values for the highest-resolution shell are in parentheses. 
A

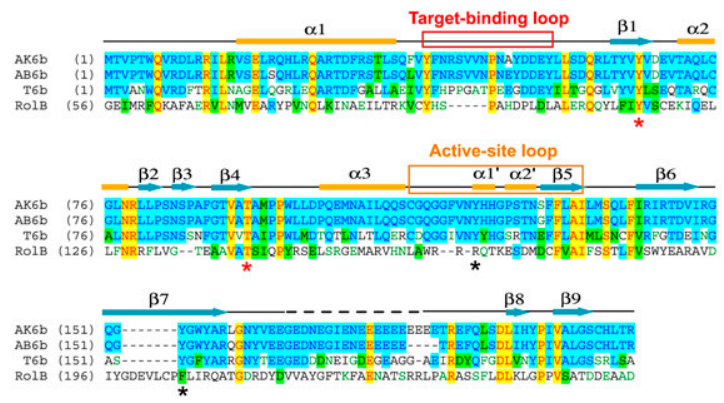

B

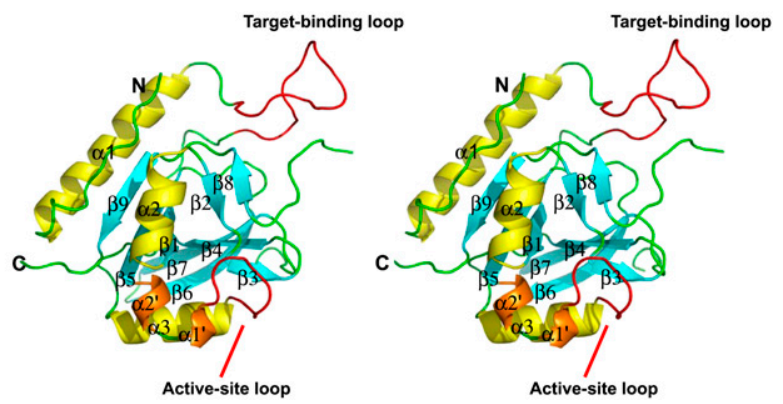

Figure 3. Sequence alignment and overall structure of Agrobacterium protein $6 \mathrm{~b}$. (A) Sequence alignment and secondary structure of Agrobacterium protein 6b. The aligned sequences are in the order of $A$. tumefaciens AK6b, A. vitis AB6b, A. vitis T6b, and Agrobacterium rhizogenes RolB. The secondary structure diagram for AK6b is shown at the top. $\alpha$ Helices are colored in yellow, and $\beta$ strands are in green. Conserved residues are shaded in cyan $(80 \%$ similarity) and green $(60 \%$ similarity), whereas essentially invariant residues are in yellow. Both the target-binding loop and the active site loop are indicated. The putative catalytic residues in $6 \mathrm{~b}$ are highlighted by a black star below the sequence alignment. $(B)$ Stereoview ribbon representation of AK6b with the target-binding loop colored in red and the active site loop colored in brown.

structure, one bulky extra density was observed sandwiched between the C-terminal loop region (residues 204-208) of 6b molecule 1 and one extended loop (residues 40-55) of $6 \mathrm{~b}$ molecule 2 (Fig. 4A). Due to the high resolution of the AK6b structure (Supplemental Fig. S3, left panel), we were able to trace most of the $\mathrm{NAD}^{+}$molecule, including the ADP and the pyro-phosphate moieties, although no $\mathrm{NAD}^{+}$molecule was added into our crystallization buffers (Supplemental Fig. S3, right panel). It is possible that the NAD ${ }^{+}$molecule might be synthesized by Escherichia coli itself and formed a complex with $6 \mathrm{~b}$. Interestingly, PJ34, a competitive inhibitor of the NAD ${ }^{+}$molecule, was packed between two cholix toxin molecules in the crystal structure of the catalytic domain of the cholix toxin (Jørgensen et al. 2008b).

The conserved loop participating in the crystal packing and the protein-protein interaction in both the AK6b and AB6b crystal structures prompted us to test whether the $6 \mathrm{~b}$ protein can self-associate, and whether this loop plays a role in the protein-protein interaction in vitro. In vitro pull-down assays showed that MBP-AK6b was able to pull down His-AK6b and His-AB6b (Fig. 4B, left panel). In contrast, MBP alone was not able to pull down His-AK6b or His-AB6b (Fig. 4B, left panel). Similarly, GST-AK6b was able to pull down His-AK6b and His-AB6b (Fig. 4B, left panel), whereas GST alone was not able to pull down HisAK6b or His-AB6b (Fig. 4B, left panel). In vitro pull-down assays further demonstrated that this extended loop (residues 40-55) indeed participates in the protein-protein interaction, because MBP-AK6b $(\Delta 40-55)$ was not able to pull down His-AK6b, whereas either GST-AK6b $(\Delta 200$ 208) or MBP-AK6b ( $\Delta 164-184)$ was able to pull down HisAK6b (Fig. 4B, right panel).

To investigate whether this extended loop (residues 4055) also plays a role in SE binding, we performed an in vitro pull-down assay. Our assay confirmed that this extended loop (residues 40-55) also plays a decisive role for SE binding, because MBP-AK6b ( $\Delta 40-55)$ was not able to pull down His-SE, whereas both GST-AK6b ( $\Delta 200-208)$ and MBP-AK6b ( $\Delta 164-184)$ were able to pull down His-SE (Fig. 4C).

To investigate whether this conserved loop also plays a general role for $6 \mathrm{~b}$ to interact with its target proteins, such as Arabidopsis Histone H3, we performed an in vitro pull-down assay by immobilizing GST-AK6b on the GST beads or MBP-AK6b on the MBP beads and incubating His-SUMO-H3 with the bound GST-AK6b or MBP-AK6b protein. As expected, both GST-AK6b and MBP-AK6b were able to pull down His-SUMO-H3, whereas neither GST nor MBP alone was able to pull down His-SUMO-H3 (Supplemental Fig. S2). Similarly, in vitro pull-down assays further demonstrated that this extended loop (residues 40-55) indeed plays a decisive role for $\mathrm{H} 3$ binding, because MBP-AK6b ( $\Delta 40-55)$ was not able to pull down His-SUMO-H3, whereas both GST-AK6b $(\Delta 200-208)$ and MBP-AK6b $(\Delta 164-184)$ were able to pull down HisSUMO-H3 (Supplemental Fig. S2).

To investigate whether this extended loop (residues 40-55) does play a significant role in vivo, we analyzed transgenic plants expressing $6 \mathrm{~b}$ mutant derivatives. Although the severe morphological phenotypes displayed by $35 S:: A K 6 b$ overexpression, such as dwarf stem and leaf serration, have been largely reverted to those of wildtype Col-0 control in $35 S:: A K 6 b(\Delta 40-55)$ mutant plants, the protein expression levels of AK6b ( $440-55)$ were dramatically decreased beyond detectable levels (data not shown). Interestingly, the introduction of the similar deletion or point mutations at 6 b overexpressed in Nicotiana tabacum and Kalanchoe daigremontiana also directly results in the significant decreased expression level of $6 \mathrm{~b}$ protein in these host plants, suggesting that these key residues probably also play a role in protein stability (Helfer et al. 2002).

\section{$6 b$ shares structural similarities with ADP-ribosylating toxins}

To investigate the molecular mechanism for $6 \mathrm{~b}$-mediated gene regulation, a three-dimensional structure homolog search was performed by using the Dali server (http:// www.ebi.ac.uk/dali). Surprisingly, the central module of the $6 \mathrm{~b}$ structure, including the two perpendicular $\beta$ sheets and the closely packed $\alpha$ helix $(\alpha 2)$, shows close 
A

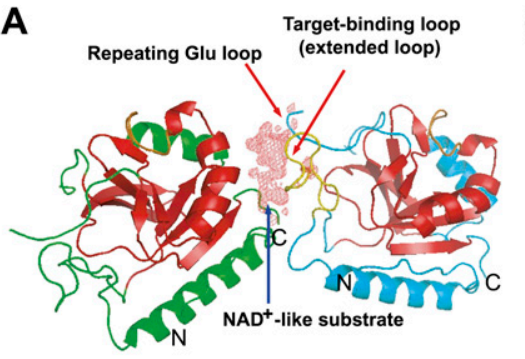

C

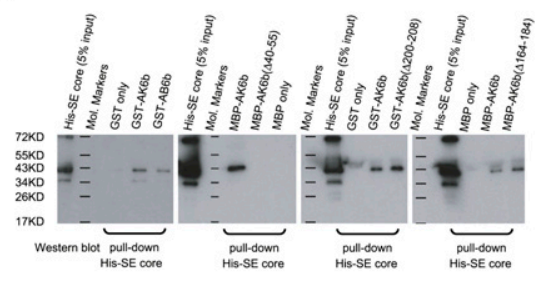

Figure 4. Protein-protein interaction loop of AK6b. (A) Crystal packing of AK6b (mediated by a putative $\mathrm{NAD}^{+}$molecule). The electron density of the $\mathrm{NAD}^{+}$-like substrate is colored in magenta, while the repeating Glu loop and the target-binding loop are indicated. (B) Self-interaction of $\mathrm{AK} 6 \mathrm{~b}$ and $\mathrm{AB} 6 \mathrm{~b}$ in vitro. The input and output of the 6 His-tagged $6 \mathrm{~b}$ target proteins were analyzed by Western blot with monoclonal antibodies to poly-His. $(C)$ In vitro pull-down assays of $6 \mathrm{~b}$ proteins with a HisSE core fragment. The input and output of the target protein His-SE core fragment were analyzed by Western blots with polyclonal antibodies to the SE core.
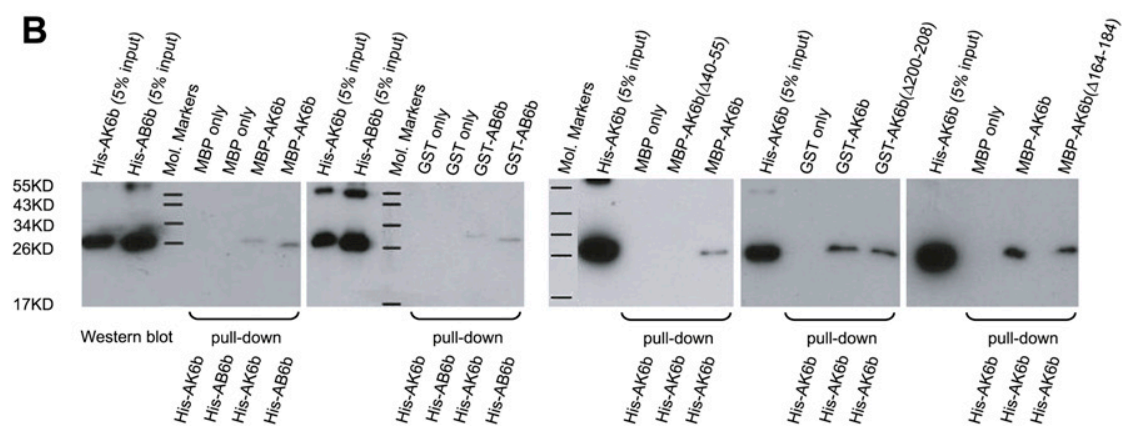

structural homology with those of the exotoxin A central module (Protein Data Bank [PBD]: 1XK9, $Z$ score 4.1, root-mean-square deviation [r.m.s.d.] 4.0.X $\AA, 100 \mathrm{C} \alpha$ ) (Yates et al. 2005) and cholera toxin central module (PDB: 1S5C, $Z$ score 3.4, r.m.s.d. $3.5 \AA$, $86 \mathrm{C} \alpha$ ) (Fig. 5A; O'Neal et al. 2004), in spite of the lack of any apparent sequence similarities among them. Notably, both exotoxin A and cholera toxin belong to ADP-ribosylating toxins with the ADP ribotransferase fold (Deng and Barbieri 2008).

However, there are significant structural differences among $6 \mathrm{~b}$, exotoxin $\mathrm{A}$, and cholera toxin, not only at the structural motifs surrounding the central modules, but also within the central modules. In general, $6 \mathrm{~b}$ adopts a more compact globular fold with more secondary structure features, whereas both exotoxin A and cholera toxin have a loose fold and less structural features within the central modules. Remarkably, the $6 \mathrm{~b}$ central module is closer to that of cholera toxin, both of them having only one $\alpha$ helix on one side and lacking the second $\alpha$ helix on the other side (Fig. 5A). More importantly, the putative $\mathrm{NAD}^{+}$substrate-binding pocket, characterized by exotoxin $\mathrm{A}$, is closed by an active site loop at both the $6 \mathrm{~b}$ and cholera toxin structures, whereas the substrate-binding pocket is opened at the exotoxin A structure (Fig. 5B). Hence, the substrate-binding pocket within $6 \mathrm{~b}$ is accessible to neither the substrate nor other proteins. Therefore, significant conformational changes are required for $6 \mathrm{~b}$ to open this pocket.

To obtain evidence that the $6 \mathrm{~b}$ protein harbors the $\mathrm{NAD}^{+}$-binding pocket, $35 S:: A K 6 b$ plants were treated with different amounts of an $\mathrm{NAD}^{+}$inhibitor, thiazole4-carboxamide adenine dinnucleotide (TAD). As expected, the morphological phenotypes accompanying $6 \mathrm{~b}$ overexpression, such as leaf serration, were gradually rescued with the addition of increasing amounts of TAD (Supplemental Fig. S4).

\section{Putative $N A D^{+}$-binding site of $6 b$}

Despite the apparently divergent sequences among $6 \mathrm{~b}$ and the ADP-ribosylating toxins, $6 \mathrm{~b}$ does share an overall structural similarity at its putative $\mathrm{NAD}^{+}$-binding pocket (Fig. 6A). In addition to the structural conserved central module formed mainly by perpendicular $\beta$ sheets that serves as the $\mathrm{NAD}^{+}$-binding pocket, $6 \mathrm{~b}$ also contains a conserved $\alpha$ helix $(\alpha 3)$ underneath the putative $\mathrm{NAD}^{+}$binding pocket (Fig. 6A). However, there is neither absolutely conserved glutamic acid residue on one side of the pocket nor conserved histidine (exotoxin A) nor arginine (cholera toxin) on the opposite side of the pocket (Fig. 6A,B). In contrast, the absolutely conserved glutamic acid on the ADP-ribosylating toxin (E553 at exotoxin A and E112 at cholera toxin) is replaced by the invariable Tyr 153 residue, and the conserved histidine or arginine residue is replaced by Tyr 66, whereas the conserved Tyr 470 and Tyr 481 residues on exotoxin A or Ser 61 and Arg 7 residues on cholera toxin are replaced by conserved Thr 93 and Tyr 121 residues (Fig. 6B).

Similar to exotoxin $\mathrm{A}$, the aromatic ring cage environment created by Tyr 121, Tyr 153, Tyr 156, and Tyr 121 probably participates in $\mathrm{NAD}^{+}$binding by anchoring the nicotinamide ring of $\mathrm{NAD}^{+}$. Tyr 66 may also stabilize $\mathrm{NAD}^{+}$binding by forming a hydrogen bond with the bound $\mathrm{NAD}^{+}$, whereas the Thr 93 side chain probably forms a hydrogen bond to the putative catalytic Y153 residue (Fig. 6B).

Similar to other bacterial ADP-ribosylating toxins, $6 \mathrm{~b}$ structures also share two crucial features around the 
A

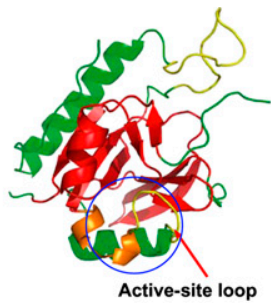

$6 b$

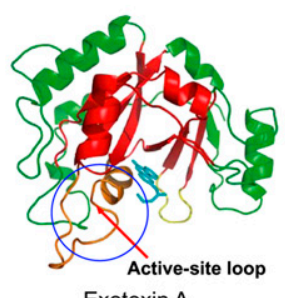

Exotoxin A

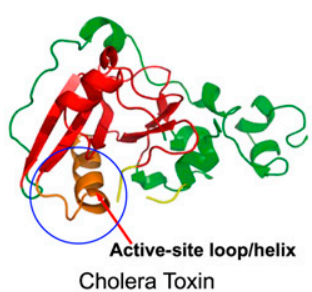

Cholera Toxin

B

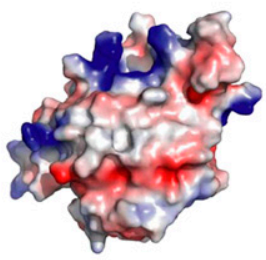

$6 b$

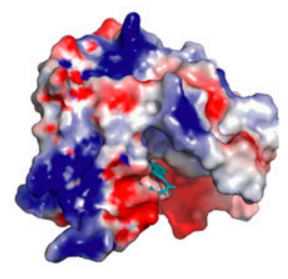

Exotoxin A

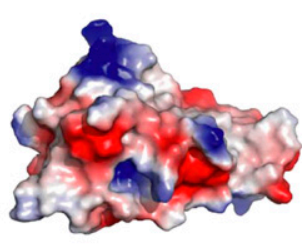

Cholera Toxin
Figure 5. AK6b adopts an ADP-ribosylating toxin fold. (A) Cartoon representation of the AK6b structure left panel), exotoxin A structure (middle panel), and cholera toxin structure (right panel). The ADP ribotransferase core domain is colored in red, whereas the structural lid covering the active site is colored in orange. $(B)$ Surface view of the AK6b structure (left panel), exotoxin A structure (middle panel), and cholera toxin structure (right panel). The view orientation is the same as in $A$.
$\mathrm{NAD}^{+}$-binding pocket: the active site loop and the ARTT motif (ADP-ribosylating toxin turn-turn motif), which consists of residues from two adjacent protruding turns (Fig. 6A; Deng and Barbieri 2008).

In the $6 \mathrm{~b}$ structure, a long well-ordered loop (residues 113-134) occludes the putative $\mathrm{NAD}^{+}$-binding site, which must relocate to allow for substrate binding (Fig. 6A). This active site loop may act as an arm to recognize ADPribose acceptor substrates. Interestingly, the conserved STS motif, probably essential for $\mathrm{NAD}^{+}$binding in most ADP-ribosylating toxins, is partially conserved at the AK6b sequence $\left({ }^{126}\right.$ STNS $\left.^{129}\right)$. Similar to other ADP-ribosylating toxins, adjacent to the putative STS motif, one highly conserved aromatic residue (Tyr 121) among all of the 6b sequences places its aromatic side chain into the putative $\mathrm{NAD}^{+}$-binding pocket, suggesting that this aromatic residue may participate in $\mathrm{NAD}^{+}$binding (Fig. 6B).

In the $6 \mathrm{~b}$ structure, a short loop (residues 148-151), together with the connected two anti-parallel $\beta$ strands ( $\beta 6$ and $\beta 7)$, is aligned well with the ARTT motif conserved at both the exotoxin A and cholera toxin structures (Fig. 6A; Supplemental Fig. S5). However, instead of the conserved Glu-X-Glu (where $\mathrm{X}$ is any amino acid) motif as catalytic residues, $6 \mathrm{~b}$ has two invariable Tyr residues (Tyr 153 and Tyr 156) probably functioning as the putative catalytic residues (Fig. 6A). In the 6b structure, the Tyr 153 side chain points toward the $\mathrm{NAD}^{+}$-binding pocket, whereas the Tyrn 156 side chain points away from the NAD ${ }^{+}$-binding pocket, suggesting that Tyr 153 may play a primary catalytic role for ADP ribosylation.

\section{Arabidopsis $A R F$ is required for $6 b$ function}

Structural comparison of $6 \mathrm{~b}$ with cholera toxin suggests that $6 \mathrm{~b}$ proteins may represent a new toxin family and may display ADP ribosylation activity. To determine the putative ADP ribosylation of $6 \mathrm{~b}$ in vitro, we performed an ADP-ribosylation assay by using in vitro expressed and purified SE as the substrate, following the method described (Armstrong and Merrill 2001). However, ADP ribosylation experiments showed that neither AK6b nor AB6b alone displays ADP ribosylation activity (Fig. 7A, lane 1; data not shown). The closely structural features between $6 \mathrm{~b}$ and cholera toxin prompted us to investigate whether $6 \mathrm{~b}$ shares the similar feature of cholera toxin, which requires a host $\mathrm{ARF}$ for $\mathrm{ADP}$ ribosylation activity. A Blast search based on the human ARF6 sequence against the Arabidopsis protein database retrieved only one sequence (Arabidopsis ARF 1A1C) sharing high sequence similarity with human ARF6 (Supplemental Fig. S6). To investigate a possible direct interaction between $6 \mathrm{~b}$ and Arabidopsis ARF, we generated N-terminal GST-fused AK6b protein and N-terminal His-fused Arabidopsis ARF protein. An in vitro pull-down assay showed that Arabidopsis ARF indeed interacts with AK6b (Fig. 7B).

To test whether Arabidopsis ARF indeed plays a crucial role for ADP ribosylation, we repeated the in vitro ADP ribosylation assay by the addition of Arabidopsis ARF together with GDP or GTP. As expected, AK6b displayed robust ADP ribosylation activity in the presence of Arabidopsis ARF and GTP (Fig. 7A, lane 4). We also introduced an alanine mutation at the putative catalytic residues identified from the crystal structures (Y66A, T93A, Y121A, and Y153A) to repeat the in vitro ADP ribosylation assay. All of these mutants displayed compromised ADP ribosylation activity (Fig. 7B, lane 5-8). In contrast, the D146A mutant with a mutation in a noncatalytic residue displayed ADP ribosylation activity similar to that of wildtype AK6b (Fig. 7B, lane 9).

To test whether AtAGO1 and/or SE is ADP-ribosylated by $6 \mathrm{~b}$ in vivo, we coimmunoprecipitated the protein complex from protein extracts of $35 S:: A K 6 b$ plants by an anti-AK6b polyclonal antibody. Then we used an antiARF monoclonal antibody to detect whether ARF is indeed tightly associated with AK6b. As expected, a clear band corresponding to the molecular weight of ARF was 
A

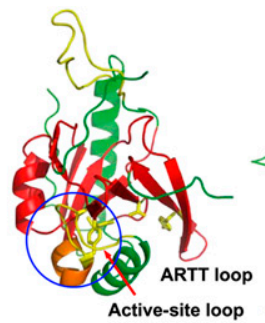

$6 b$

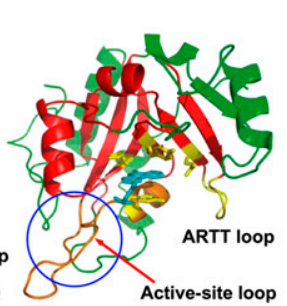

Exotoxin A

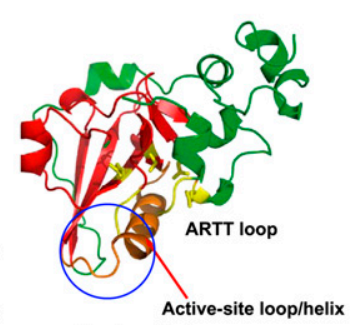

Cholera Toxin
B

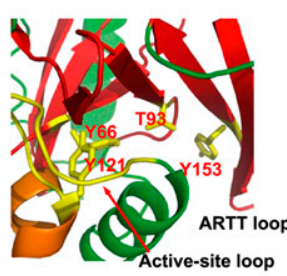

$6 b$

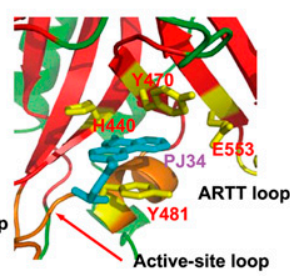

Exotoxin A

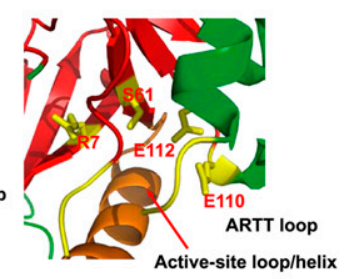

Cholera Toxin
Figure 6. Putative active site of AK6b. (A) Overall view of putative active pockets of AK6b (left panel), exotoxin A (middle panel), and cholera toxin (right panel). The structure of the similar $\mathrm{NAD}^{+}$-binding domain is colored in red and other subdomains are in green, whereas the putative active site loop is in orange. Both the active site loop and ARTT loop are indicated. (B) Detailed view of putative active pockets of AK6b (left panel), exotoxin A (middle panel), and cholera toxin (right panel). Catalytic residues involved in $\mathrm{NAD}^{+}$ binding are indicated and are colored in yellow. detected by Western blot (Fig. 7C). These experiments demonstrated that ARF is indeed the protein partner of $6 \mathrm{~b}$ in vivo, and strongly support the notion that both SE and AGO1 are ADP-ribosylated by $6 \mathrm{~b}$ in vivo.

To investigate whether these residues play significant roles for the miRNA-deficient phenotype displayed by $35 S:: A K 6 b$ plants, we performed a transgenic plant screen assay. Although the miRNA-deficient phenotype has been largely reversed at $35 S:: A K 6 b$ (Y66A, T93A, Y121A, or Y153A) mutants, the protein expression levels of AK6b mutants (Y66A, T93A, Y121A, or Y153A) in vivo were dramatically decreased beyond detectable levels (data not shown). In contrast, the $35 S:: A K 6 b$ (D146A) mutant showed a similar miRNA-deficient phenotype, and the protein expression level of the mutant in vivo was readily detectable (data not shown).

\section{Crystal structure of Arabidopsis ARF resembles human ARF6 structure}

To further investigate the molecular mechanism of ADP ribosylation catalyzed by $6 \mathrm{~b}$ in the presence of ARF, we successfully determined the crystal structure of Arabidopsis ARF in complex with GDP at $1.8 \AA$, with crystallographic statistics summarized in Table 1. Arabidopsis ARF shares high structural similarity to human ARF6 (Fig. 7D). Similar to human ARF6, the N-terminal $\alpha$ helix of Arabidopsis ARF is positioned in the hydrophobic pocket opposite the GDP-binding site, whereas GDP$\mathrm{Mg}^{2+}$ is deeply buried in the protein core and interacts with the switch regions (Fig. 7D, left panel). Therefore, a similar dramatic conformational change, including the rearrangements of the $\mathrm{N}$ terminus and switch regions triggered by GTP hydrolysis, should be expected for Arabidopsis ARF. The close structural similarity between Arabidopsis ARF and human ARF6 in complex with GDP (Fig. 7D, middle panel) suggests that Arabidopsis ARF in complex with GTP might adopt the similar conforma- tion, as revealed by the human ARF6-GTP structure (Fig. 7D, right panel).

\section{Discussion}

\section{$6 b$ directly targets miRNA machineries}

Interference with RNA silencing by viral suppressors represents an anti-host defense response by viral pathogens (for review, see Yang and Yuan 2009). T-DNAs can be considered to be functionally related to a DNA virus. The observation that $35 S:: A K 6 b$ plants display a morphological phenotype similar to that of $35 S:: F N Y 2 b$ plants raises the question of whether protein $6 \mathrm{~b}$ functions as an RNA silencing suppressor (Zhang et al. 2006b). The partially overlapping morphological and molecular phenotypes between $35 S:: A K 6 b$ plants and ago1-27 and se-1 mutant plants further suggest that $6 \mathrm{~b}$ probably interferes with miRNA pathways (Fig. 1). Our results show that AK6b probably executes its suppressor function by directly targeting SE and AGO1, two key components of the miRNA machineries in Arabidopsis (Fig. 2). We also mapped the primary targeting region on AGO1 to the $\mathrm{N}$-terminal domain adjacent to the RNA entrance groove and the primary interacting regions on SE to the proteinprotein interaction platform, including the N-terminal domain and the Mid domain (Fig. 1B,D).

The specific $6 \mathrm{~b} / \mathrm{SE}$ and $6 \mathrm{~b} / \mathrm{AGO} 1$ interactions probably suggest that not only RISC/AGO1 but also DCL1-SEHYL1 are essential protein complexes that participate in virus-induced gene silencing (VIGS) to defend against offending viruses. Compared with other viral suppressors primarily targeting on AGO1, such as CMV2b and P0 (Zhang et al. 2006b; Baumberger et al. 2007; Bortolamiol et al. 2007), the $6 \mathrm{~b}$ protein targets a wide range of host proteins residing inside the nucleus (Kitakura et al. 2002, 2008; Terakura et al. 2007). The ADP ribotransferase fold displayed by the $6 \mathrm{~b}$ structure enables $6 \mathrm{~b}$ to function as an 
A

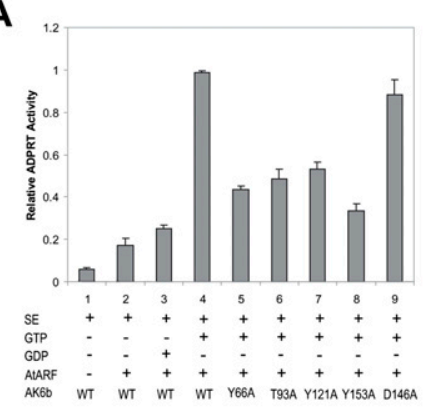

B

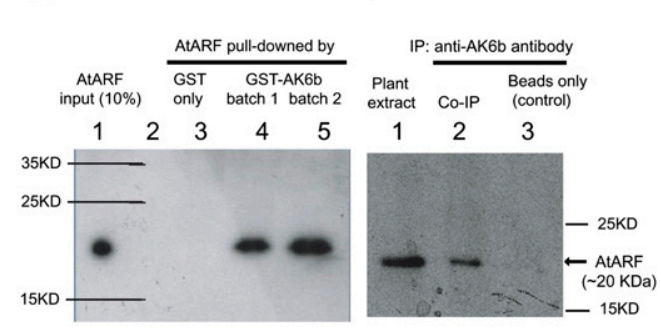

D
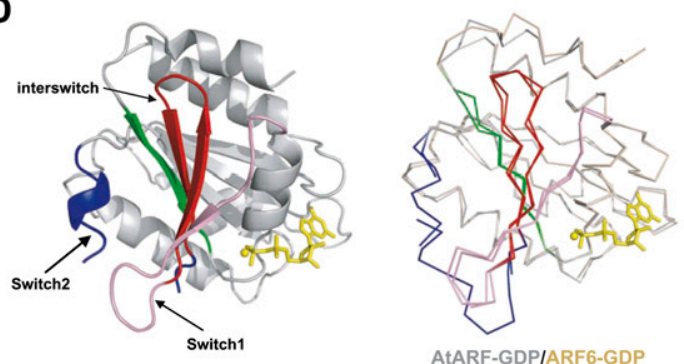

AtARF-GDPIARF6-GDP

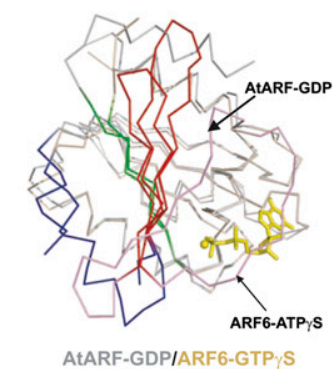

AtARF-GDPIARF6-GTPYS

E

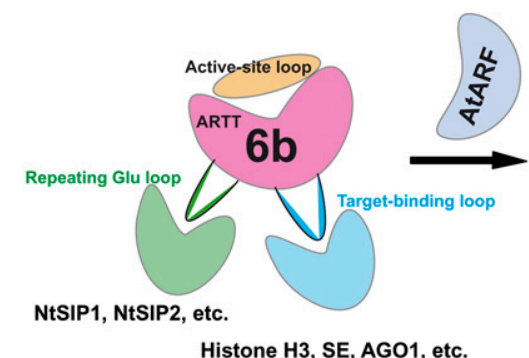

Histone H3, SE, AGO1, etc.

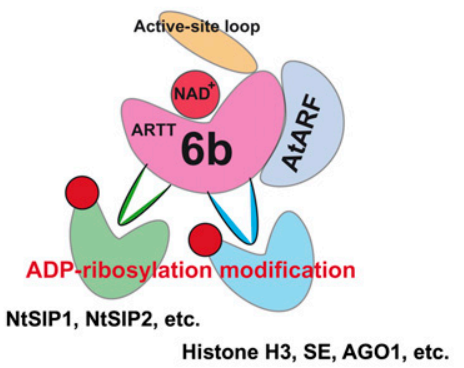

Figure 7. AK6b is a novel ADP-ribosylating toxin. $(A)$ AK6b catalyzes ADP ribosylation of SE in the presence of GTP. The relative ADP ribosylation activity after each reaction is shown by the bars. The substrate, enzyme, cofactors, and ARF used for experiments are shown below the chart. (Lanes 1-4) Wild-type AK6b. (Lanes 5-9) Point mutations of AK6b. $(B)$ In vitro pulldown assay of GST-AK6b interaction with His-AtARF. GST-AK6b was immobilized on GST beads and incubated with fulllength His-ARF. Bound GST-AK6b was retrieved, and the association of His-ARF was monitored by Western blots using monoclonal antibodies against poly-His. (Lane 1) Input control. (Lane 2) Molecular marker size positions. (Lane 3) GST only. (Lane 4) GST-AK6b (protein batch 1). (Lane 5) GSTAK6b (protein batch 2). (C) Interaction of $\mathrm{ARF}$ and AK6b in Arabidopsis plants in vivo. Two-week-old seedlings expressing $35 S:: A K 6 b$ were treated overnight with 50 $\mu \mathrm{M}$ MG132. Total protein extracts were immunoprecipitated (IP) with polyclonal antibody to AK6b. Western blots were analyzed with a human ARF monoclonal antibody to detect Arabidopsis ARF in vivo. (Lane 1) Input, plant extract only. (Lane 2) Eluent pulled down from beads bound with AK6b antibody. (Lane 3) Eluent pulled down from beads without AK6b antibody bound (negative control). (D) Crystal structure of Arabidopsis ARF (AtARF). (Left panel) Cartoon representation of AtARF in complex with GDP- $\mathrm{Mg}^{2+}$. Switch1, switch2, and interswitch are colored in pink, blue, and red, respectively. (Middle panel) Ribbon presentation of superimposition of AtARF in complex with GDP-Mg ${ }^{2+}$ with human ARF6 in complex with GDP-Mg ${ }^{2+}$. AtARF is colored in gray, whereas human ARF6 is colored in wheat. The color code for switch1, switch2, and interswitch is the same as that used in the left panel. (Right panel) Ribbon presentation of superimposition of AtARF in complex with GDP- $\mathrm{Mg}^{2+}$ with human ARF6 in complex with GTP $\gamma$ S. AtARF is colored in gray, whereas human ARF6 is colored in wheat. The color code for switch1, switch2, and interswitch is the same as that used in the left panel. (E) A hypothetical working model for ADP ribosylation of substrate catalyzed by $6 \mathrm{~b}$ in the presence of ARF. (Left panel) The $6 \mathrm{~b}$ protein trapped at cofactor-free conformation. (Right panel) The $6 \mathrm{~b}$ protein trapped at the ARF-bound activation form. Highly conserved repeating Glu loop and target-binding loop used for substrates binding.

ADP-ribosylating toxin to target many host proteins with apparently completely different functions.

Interestingly, although both $6 \mathrm{~b}$ and CMV2b target AGO1 to interfere with the miRNA pathway in plants, the primary target of $6 \mathrm{~b}$ seems to be $\mathrm{SE}$, because the miRNA expression levels in $35 S:: A K 6 b$ plants are dramatically decreased (Fig. 1B). This is not surprising, because SE functions upstream of AGO1.

\section{$6 b$ belongs to a novel toxin family}

Although having limited sequence homology, ADP-ribosylating toxins share common core structures for $\mathrm{NAD}^{+}$ binding (Fig. 3). However, the toxins can be divided into two groups, with the DT group represented by exotoxin A and the CT group represented by cholera toxin. The completely different sets of catalytic residues within the active site used by these two different toxin groups (DT vs. CT) strongly suggest that the mechanisms of substrate recognition could be different (Deng and Barbieri 2008).

In the exotoxin A structure, the active site is composed of the characteristic residues Glu 553, His 440, Tyr 481, and Tyr 470 (Fig. 6B, middle panel). Glu 553 forms a hydrogen bond with the $2^{\prime} \mathrm{OH}$ of N-ribose of $\mathrm{NAD}^{+}$ and orientates the dinucleotide substrate for nucleophilic attack, whereas His 440, Tyr 481, and Tyr 470 stabilize the bound $\mathrm{NAD}^{+}$substrate (Fig. $6 \mathrm{~B}$, middle panel). Moreover, a comparison of the structures of apo-exotoxin A and that of the EF2 complex demonstrated that the contact surface between exotoxin A and its EF2 target is rather small, and the conformational changes are marginal on $\mathrm{NAD}^{+}$binding or EF2 binding or during the substrate catalysis process (Jørgensen et al. 2005, 2008a). 
In contrast, in the cholera toxin structure, the active site is composed of the characteristic residues Arg 7, Ser 61, Glu 110, and Glu 112, which are occluded by the active site loop (residues 47-56, cholera toxin residue number) (Fig. 6B, right panel). Upon binding to its partner protein, such as ARF6-GTP, this loop swings out of the active site to expose residues for substrate binding and catalysis (Lobet et al. 1991; Cieplak et al. 1995; van den Akker et al. 1996; O’Neal et al. 2004, 2005).

The $6 \mathrm{~b}$ protein contains a conserved central module resembling the overall structural similarity to the $\mathrm{NAD}^{+}$binding pockets of all of the ADP-ribosylating toxins discovered so far, although there is no apparent sequence similarity between $6 \mathrm{~b}$ and the ADP-ribosylating toxins. Moreover, $6 \mathrm{~b}$ contains a completely different set of catalytic residues within the putative $\mathrm{NAD}^{+}$-binding pocket, suggesting that $6 \mathrm{~b}$ may represent a novel family of ADP-ribosylating toxins (Fig. 6B, left panel). The well-conserved Glu (exotoxin A and cholera toxin) or His/Arg (exotoxin A/cholera toxin) is not found within the $6 \mathrm{~b}$ active site pocket. Instead, highly conserved Tyr 66 and Tyr 153 residues are employed to supplant the functions of Glu and His/Arg residues, respectively. In addition, the critical highly conserved Thr 93 probably plays the same functional role as Tyr 470 at exotoxin A or Ser 61 at cholera toxin by forming hydrogen bonds with the catalytic Tyr 153 residue to facilitate ADP ribosylation (Fig. 6B, left panel). Our in vitro ADP ribosylation assay unambiguously demonstrated that the highly conserved Y66, T93, Y121, and Y153 play significant roles for ADP ribosylation in vitro (Fig. 7A, lane 5-8).

Furthermore, similar to cholera toxin, the active site pocket of $6 \mathrm{~b}$ is occluded by the active site loop (residues 113-134) (Fig. 6A [left panel], B [left panel]). Therefore, significant conformational changes are required to expose this active site pocket to allow for $\mathrm{NAD}^{+}$access. Consistent with this structural observation, $6 \mathrm{~b}$ does not display any $\mathrm{ADP}$ ribosylation function in vitro on any target proteins discovered so far (Fig. 7A, lane 1; data not shown). Indeed, Arabidopsis ARF and GTP are both needed to trigger the conformational change of $6 \mathrm{~b}$ for target binding (Fig. 7A, lane 4).

\section{Potential roles of $6 b$ on plant gene regulation and cell growth}

6b proteins interact with many different host proteins involved in the expression of genes related to plant cell proliferation, and various hypotheses have been proposed to explain the effects of $6 \mathrm{~b}$ on plant cell growth. The repeating Glu residue loop (residues 164-184) was reported to interact with NtSIP1, which contains the trihelix motif (Kitakura et al. 2002), and NtSIP2, which is homologous to the TNP1 protein (Kitakura et al. 2008). However, the $6 \mathrm{~b} \Delta \mathrm{A}$ mutant protein (lacking the repeating Glu residue loop 164-184) retains the ability to interact with Arabidopsis histone H3, SE, and AGO1 (Terakura et al. 2007; this study). It appears that there are two groups of proteins interacting with $6 \mathrm{~b}$ : one group targeting this acidic loop, and the other group targeting other structural elements. The acidic loop (residues 164-184), which may serve as a structural scaffold for protein-protein or protein-nucleic acid interaction, is disordered in both the AK6b and AB6b structures. In contrast, we identified one well-ordered loop (residues 40-55) that serves as a structural scaffold for Arabidopsis histone H3, AGO1, and SE binding (Fig. 4; Supplemental Fig. S2).

The fact that the $6 \mathrm{~b}$ protein targets a wide range of diversified host proteins in plants suggests that the phenotypes generated by $6 \mathrm{~b}$ expression are a consequence of its interaction with a number of proteins. On one hand, $6 \mathrm{~b}$ might function as a transcriptional coactivator/mediator by binding to proteins involved in the transcription machinery, and this binding may be mediated by the repeating acidic Glu residue loop. On the other hand, $6 \mathrm{~b}$ might function as an ADP-ribosylating toxin by targeting key components in the miRNA processing/silencing machinery using the well-ordered extended loop /residues 40$55)$ as an interacting platform. The ectopic expression of a number of genes-such as class I KNOX, CUC, and cell cycle-related genes-caused by $6 \mathrm{~b}$ expression probably depends on the general ADP ribosylation activity of $6 \mathrm{~b}$. Because covalent modifications of host proteins catalyzed by $\mathrm{ADP}$ ribosylation often result in an inactivation of the targets, the ADP ribosylation activity of $6 \mathrm{~b}$ is likely responsible for the various developmental abnormalities of 35S::AK6b plants, including leaf curling, serration, and dwarfism. ADP ribosylation modification of host target proteins by $6 \mathrm{~b}$ may result in an inactivation of the target proteins that eventually changes cell physiology and even produces tumors (Fig. 7E). Consistent with this hypothesis, the mutations on the conserved ADP ribosylation catalytic residues Tyr 66 or Thr 93 lead to a loss of $6 \mathrm{~b}$ oncogenicity (Helfer et al. 2002). Moreover, the abnormal growth of calli induced by $6 \mathrm{~b}$ is probably also dependent on the $\mathrm{ADP}$ ribosylation activity, because the $6 \mathrm{~b} \Delta \mathrm{C}$ mutant protein (lacking residues 164-208), which disrupts the overall ADP ribosylation fold, did not elicit any abnormal growth of calli (Kitakura et al. 2002; Terakura et al. 2007). Alternatively, the loss of phenotype may be due to the instability of these $6 \mathrm{~b}$ mutant proteins in vivo, although the mutant proteins expressed at the E. coli system show protein stabilities similar to those of the wild type.

Although the $6 b$ gene might play only a minor role in crown gall formation, it could play a much more important role in tumorigenicity in certain host species (Garfinkel et al. 1981; Joos et al. 1983; Hooykaas et al. 1988; Tinland et al. 1989, 1992). These observations are also consistent with our structural and functional evidence that the $6 \mathrm{~b}$ protein might be a novel ADPribosylating toxin that has certain host target specificity. A major challenge in the future will be to determine the crystal structure of the quadruple complex 6b-ARFGTP-substrate, which will eventually help to uncover the molecular mechanism of $6 \mathrm{~b}$ action.

\section{Materials and methods}

\section{Plant material}

Arabidopsis thaliana (se-1, ago1-27 mutant, and all $6 b$ transgenic plants) was grown under 16 -h light and 8 -h dark conditions at $22^{\circ} \mathrm{C}$. 


\section{Construction of plasmids}

Plasmids and their relevant characteristics are listed in Supplemental Table S1. All manipulations for plasmid construction were performed using standard techniques (Sambrook et al. 1989), and constructs were verified by sequencing. E. coli DH5 $\alpha$ was used as a host for plasmid construction.

A series of 6b-related vectors was constructed as follows. Fulllength $A K 6 b$ from pTiAKE10 and $A B 6 b$ from pTiAB4 were cloned using the same specific primers: $5^{\prime}$-ATGACGGTTCC TACTTGG-3' and 5'-CTAACGTGTGAGATGGCAC-3'. Mutants of $A K 6 b$ were prepared by overlapping PCR. The PCR fragments for protein expression in E. coli with an His tag, GST tag, or MBP tag were digested with NdeI/XhoI, EcoRI/XhoI, or EcoRI/HindIII. The resulting fragments were ligated into pET-28b (kanamycin selection; Novagen), pGEX-6p-1 (ampicillin selection; Novagen), or pMAL-c2X (ampicillin selection; Novagen) vectors, respectively, to yield pET-AK6b and pET-AB6b; pGEX-AK6b, pGEX-AB6b, and pGEX-200; and pMAL-40 and pMAL-164. The PCR fragments for the transformation of Arabidopsis were digested with $\mathrm{XbaI} / \mathrm{SacI}$. The resulting fragments were linked to the cauliflower mosaic virus P35S in the binary vector pBI121 to yield p121-AK6b, p121-40, p121-66, p121-93, p121-116, p121-121, p121-123, and p121-146.

$A R F 1 A 1 C$ was cloned from Col-O cDNA using the primers 5'-GATGCAcatATGGGGTTGTCATTCGG-3' and 5' -GTAGCT ctcgagTTACTATGCCTTGCTTGCGAT-3'. PCR product was digested with NdeI/XhoI and inserted into pET-28b to yield N-His-ARF.

\section{Production of transgenic plants}

Supplemental Table S1 lists the binary plasmids used in this study. Mutated versions of AK6b were generated by overlapping PCR. A. thaliana (Col-O) plants were transformed by Agrobacterium (EHA105 strain)-mediated infiltration using the floral dipping method (Clough and Bent 1998; Zhang et al. 2006a).

\section{Generation and selection of antibodies}

The SE core domain (195-544) and Thermus thermophilic AGOlike protein were subjected to monoclonal antibodies preparation, whereas full-length AK6b was subjected to polyclonal antibody preparation using standard protocols. We obtained eight different monoclonal antibodies against the Thermus thermophilic AGOlike protein and six different monoclonal antibodies against the SE core domain (195-544). We systematically screened all eight Thermus thermophilic AGO-like antibodies against the wild-type Arabidopsis and Flag-AGO1 line. At the end, we obtained one antibody that specifically recognizes AtAGO1 (Supplemental Fig. S1). Similarly, we were able to get a monoclonal antibody against full-length SE.

\section{In vitro pull-down assays and co-IP experiments}

Fifty micrograms of His-tagged target proteins was preabsorbed in the binding buffer, including amylose resin (Biolabs) or glutathione-agarose beads (GE Healthcare), before the MBP-tagged or GST-tagged bait proteins were added. Pulled-down proteins were resolved by SDS-PAGE and detected by Western blot.

For the co-IP experiments, $\sim 0.3 \mathrm{~g}$ of frozen tissue was homogenized in $0.75 \mathrm{~mL}$ of lysis buffer and spun down to remove debris. The supernatant was precleared with $100 \mu \mathrm{L}$ of protein-A gel for 1 $\mathrm{h}$, and then collected to be incubated with $4 \mu \mathrm{g}$ of anti-AK6b antibody for $1 \mathrm{~h}$. The antibody associated with the protein complex was pulled down with $40 \mu \mathrm{L}$ of protein-A gel, followed by washing five times in the lysis buffer. The protein complex was eluted for $5 \mathrm{~min}$ on a $100^{\circ} \mathrm{C}$ heat block. The eluted protein mixture was resolved on 15\% SDS-PAGE gel and transferred onto a PVDF membrane. Western blots were analyzed with a polyclonal antibody specific to SE or $\mathrm{H} 3$, or with a monoclonal antibody specific to ARF.

\section{Northern blot analysis}

For analysis of miRNAs, total RNA was separated on denaturing $15 \%$ TBE-urea gels. Probe detection was performed using the LightShift Chemiluminescent EMSA kit (ThermoFisher Scientific, Inc.) according to the manufacturer's protocol.

\section{Real-time RT-PCR}

Total RNA was isolated from the aerial parts of 20-d-old wildtype, se-1, and 35S::AK6b seedlings using Trizol reagent (Invitrogen). Reverse transcription was performed with $2 \mu \mathrm{g}$ of total RNA using the First Strand cDNA Synthesis kit (Fermentas, Inc.). PCR was carried out in the presence of the dsDNA-specific dye SYBR Green (Applied Biosystems). Amplification was monitored in real time with the 7500 Real-Time PCR System (Applied Biosystems).

\section{Protein purification}

His or His-SUMO fusion proteins include His-AK6b, His-AB6b, His-SE, and His-ARF. GST-tagged proteins include GST-AK6b, GST-AB6b, GST-AK6b (D200-208), GST-AK6b (Y66A), GSTAK6b (T93A), GST-AK6b (Y121A), GST-AK6b (D146A), GSTAK6b (Y153A), GST-SE-Mid, and GST-SE-NT. MBP fusion proteins include MBP, MBP-AK6b $(\Delta 40-55)$, MBP-AK6b $(\Delta 164-$ 184), MBP-AGO1-PolyQ, MBP-AGO1-NT, MBP-AGO1-PAZ, MBP-AGO1-Mid, MBP-AGO1-PIWI1, and MBP-AGO1-PIWI2. All proteins were expressed in E. coli and purified using affinity columns, followed by size exclusion column chromatography.

\section{In vitro $A D P$ ribosylation assay}

The in vitro ADP ribosylation assay was carried out as described previously (Armstrong and Merrill 2001). Each reaction contained $350 \mu \mathrm{M} \varepsilon-\mathrm{NAD}^{+}, 20 \mu \mathrm{M} \mathrm{SE}, 1 \mu \mathrm{M}$ ARF1A1C, and $500 \mu \mathrm{M}$ GTP or GDP. Following temperature equilibration for $10 \mathrm{~min}$ in buffer $(20 \mathrm{mM}$ Tris- $\mathrm{HCl}$ at $\mathrm{pH} 7.8)$ the reaction was initiated by the addition of wild-type AK6b or its mutant derivatives $(1 \mu \mathrm{M})$. Fluorescence was measured using an xMarkTM Microplate Spectrophotometer (Bio-Rad) with a $305-\mathrm{nm}$ excitation wavelength.

\section{Crystallization and data collection}

Crystals of AK6b were grown by hanging-drop vapor diffusion at $20^{\circ} \mathrm{C}$. Typically, a $2-\mu \mathrm{L}$ hanging drop contained $1.0 \mu \mathrm{L}$ of protein $(8 \mathrm{mg} / \mathrm{mL})$ mixed with $1.0 \mu \mathrm{L}$ of reservoir containing $0.3 \mathrm{M}$ magnesium formate and 0.1 M Bis-tris buffer ( $\mathrm{pH}$ 5.9), and was equilibrated over $1 \mathrm{~mL}$ of reservoir solution. The crystals grew to a maximum size of $0.2 \mathrm{~mm} \times 0.2 \mathrm{~mm} \times 0.1 \mathrm{~mm}$ over the course of $2 \mathrm{~d}$.

Crystals of AB6b were grown by hanging-drop vapor diffusion at $20^{\circ} \mathrm{C}$. Typically, a $2-\mu \mathrm{L}$ hanging drop contained $1.0 \mu \mathrm{L}$ of protein $(12 \mathrm{mg} / \mathrm{mL})$ mixed with $1.0 \mu \mathrm{L}$ of reservoir containing $0.35 \mathrm{M}$ ammonium dehydrate phosphate and $0.1 \mathrm{M}$ sodium citrate $(\mathrm{pH} \mathrm{5.8)}$, and was equilibrated over $1 \mathrm{~mL}$ of reservoir solution. These crystals grew to a maximum size of $0.05 \mathrm{~mm} \times$ $0.05 \mathrm{~mm} \times 0.02 \mathrm{~mm}$ over the course of $7 \mathrm{~d}$. 
Crystals of Arabidopsis ARF were grown with GDP by hanging-drop vapor diffusion at $20^{\circ} \mathrm{C}$. Typically, a $2-\mu \mathrm{L}$ hanging drop contained $1.0 \mu \mathrm{L}$ of protein $(15 \mathrm{mg} / \mathrm{mL})$ mixed with $1.0 \mu \mathrm{L}$ of reservoir containing 25\% PEG6000, $0.2 \mathrm{M}$ magnesium chloride, and 0.1 M HEPES (pH 7.2), and was equilibrated over $1 \mathrm{~mL}$ of reservoir solution. These crystals grew to a maximum size of $0.15 \mathrm{~mm} \times 0.15 \mathrm{~mm} \times 0.02 \mathrm{~mm}$ over the course of $10 \mathrm{~d}$.

For data collection, AK6b crystals were flash-frozen $\left(100^{\circ} \mathrm{K}\right)$ in the above reservoir solution supplemented with $30 \%$ glycerol. A total of 360 frames of $1^{\circ}$ oscillation was collected for each crystal per wavelength. A total of three wavelengths' data was collected, corresponding to selenium peak (0.9790 ̊), inflection (0.9794 $\mathrm{A})$, and remote $(0.96 \AA)$. The data were collected on the beamline $\mathrm{X} 12 \mathrm{C}$ at the National Synchrotron Light Source at Brookhaven National Laboratory, and was processed by HKL2000 (http:// www.hkl-xray.com). The crystals belong to space group $\mathrm{P} 3{ }_{2} 21$, with the unit cell parameters listed in Table 1.

AB6b crystals were flash-frozen $\left(100^{\circ} \mathrm{K}\right)$ in the reservoir solution supplemented with $30 \%$ glycerol. A total of 360 frames of $1^{\circ}$ oscillation was collected at wavelength $1.1 \AA$ on the beamline X29 at the National Synchrotron Light Source at Brookhaven National Laboratory, and was processed by HKL2000 (http:// www.hkl-xray.com). The crystals belong to space group $\mathrm{P} 2_{1} 2_{1} 2$, with the unit cell parameters listed in Table 1.

Arabidopsis ARF crystals were flash-frozen $\left(100^{\circ} \mathrm{K}\right)$ in the reservoir solution. A total of 360 frames of $1^{\circ}$ oscillation was collected at wavelength $1.075 \AA$ on the beamline X29 at the National Synchrotron Light Source at Brookhaven National Laboratory, and was processed by HKL2000 (http://www.hklxray.com). The crystals belong to space group $\mathrm{P} 2{ }_{1} 2{ }_{1} 2$, with the unit cell parameters listed in Table 1.

\section{Structure determination}

The crystal structure of AK6b was determined by MAD using SOLVE/RESOLVE (http://www.solve.lanl.gov), and the MAD phase was calculated and improved by density modification, assuming a solvent content of $\sim 48 \%$ using the SHARP program (http://www.globalphasing.com). The crystal structure of AB6b was determined by molecular replacement, with the AK6b structure as the search model. The crystal structure of Arabidopsis ARF was determined by molecular replacement, with the human ARF6 structure (PDB ID: 1RRF) as the search model. The models were built by using the program $\mathrm{O}$ and were refined using REFMAC/CCP4. The R-free set contained $5 \%$ of the reflections, chosen at random. The model comprises residues 5-208 (AK6b), 1-204 (AB6b), or 4-180 (AtARF). The disordered region-including loop segment 166-182 (AK6b), 167-179 (AB6b), or 70-76 (AtARF)-was not included in the model.

Further information about the mutant lines, sample preparation, primer sequences, reactions, and data analysis can be found in the Supplemental Material.

\section{Accession codes}

Coordinates and the structure factors have been deposited to $\mathrm{PDB}$ with accession codes 3AQ2 (AB6b), 3AQ3 (AK6b), and 3AQ4 (Arabidopsis ARF1A1C).

\section{Acknowledgments}

We thank Dr. Y. Machida for AK6b, Dr. L. Otten for AB6b, and A. Soares at the National Synchrotron Light Source at the Brookhaven National Laboratory for assistance with data collection. This work was supported by the Singapore Ministry of Education (T208A3124 to Y.A.Y.) and intramural research funds from Temasek Life Sciences Laboratory. Work done at the Rockefeller University was supported by NIH grant GM44640 to N.-H.C. M.W. performed biochemical, genetic, and crystallographic work; S.M. detected the interaction between AK6b and ARF in vivo under the supervision of Y.A.Y.; N.-H.C. and T.S. interpreted the $6 \mathrm{~b}$ transgenic plant phenotype; T.S. identified/ characterized the interaction between AK6b and AGO1; J.-Y.Y. and C.J. identified/characterized the interaction between AK6b and SE under the supervision of N.-H.C.; and Y.A.Y., M.W., and N.-H.C. wrote the manuscript.

\section{References}

Armstrong S, Merrill AR. 2001. Application of a fluorometric assay for characterization of the catalytic competency of a domain III fragment of Pseudomonas aeruginosa exotoxin A. Anal Biochem 292: 26-33.

Baumberger N, Tsai CH, Lie M, Havecker E, Baulcombe DC. 2007. The Polerovirus silencing suppressor P0 targets Argonaute proteins for degradation. Curr Biol 17: 16091614.

Bortolamiol D, Pazhouhandeh M, Marrocco K, Genschik P, Ziegler-Graff V. 2007. The Polerovirus F box protein P0 targets ARGONAUTE1 to suppress RNA silencing. Curr Biol 17: 1615-1621.

Cieplak W Jr, Mead DJ, Messer RJ, Grant CC. 1995. Site-directed mutagenic alteration of potential active-site residues of the A subunit of Escherichia coli heat-labile enterotoxin. Evidence for a catalytic role for glutamic acid 112.J Biol Chem 270: 30545-30550.

Clément B, Pollmann S, Weiler E, Urbanczyk-Wochniak E, Otten L. 2006. The Agrobacterium vitis T-6b oncoprotein induces auxin-independent cell expansion in tobacco. Plant J 45: 1017-1027.

Clément B, Perot J, Geoffroy P, Legrand M, Zon J, Otten L. 2007. Abnormal accumulation of sugars and phenolics in tobacco roots expressing the Agrobacterium T-6b oncogene and the role of these compounds in 6b-induced growth. Mol Plant Microbe Interact 20: 53-62.

Clough SJ, Bent AF. 1998. Floral dip: A simplified method for Agrocacterium-mediated transformation of Arabidopsis thaliana. Plant I 16: 735-743.

Deng Q, Barbieri JT. 2008. Molecular mechanisms of the cytotoxicity of ADP-ribosylating toxins. Annu Rev Microbiol 62: 271-288.

Gális I, Simek P, Van Onckelen HA, Kakiuchi Y, Wabiko H. 2002. Resistance of transgenic tobacco seedlings expressing the Agrobacterium tumefaciens C58-6b gene, to growthinhibitory levels of cytokinin is associated with elevated IAA levels and activation of phenylpropanoid metabolism. Plant Cell Physiol 43: 939-950.

Gális I, Kakiuchi Y, Simek P, Wabiko H. 2004. Agrobacterium tumefaciens AK-6b gene modulates phenolic compound metabolism in tobacco. Phytochemistry 65: 169179.

Garfinkel DJ, Simpson RB, Ream LW, White FF, Gordon MP, Nester EW. 1981. Genetic analysis of crown gall: Fine structure map of the T-DNA by site-directed mutagenesis. Cell 27: 143-153.

Grémillon L, Helfer A, Clément B, Otten L. 2004. New plant growth-modifying properties of the Agrobacterium T-6b oncogene revealed by the use of a dexamethasone-inducible promoter. Plant J 37: 218-228.

Helfer A, Pien S, Otten L. 2002. Functional diversity and mutational analysis of Agrobacterium 6B oncoproteins. Mol Genet Genomics 267: 577-586. 
Helfer A, Clément B, Michler P, Otten L. 2003. The Agrobacterium oncogene $\mathrm{AB}-6 \mathrm{~b}$ causes a graft-transmissible enation syndrome in tobacco. Plant Mol Biol 52: 483-493.

Hooykaas PJJ, Den Dulk-Ras H, Schilperoort RA. 1988. The Agrobacterium tumefaciens T-DNA gene $6^{\mathrm{b}}$ is an onc gene. Plant Mol Biol 11: 791-794.

Huss B, Tinland B, Paulus F, Walter B, Otten L. 1990. Functional analysis of a complex oncogene arrangement in biotype III Agrobacterium tumefaciens strains. Plant Mol Biol 14: 173186.

Joos H, Inzé D, Caplan A, Sormann M, Van Montagu M, Schell J. 1983. Genetic analysis of T-DNA transcripts in nopaline crown galls. Cell 32: 1057-1067.

Jørgensen R, Merrill AR, Yates SP, Marquez VE, Schwan AL, Boesen T, Andersen GR. 2005. Exotoxin A-eEF2 complex structure indicates ADP ribosylation by ribosome mimicry. Nature 436: 979-984.

Jørgensen R, Wang Y, Visschedyk D, Merrill AR. 2008a. The nature and character of the transition state for the ADPribosyltransferase reaction. EMBO Rep 9: 802-809.

Jørgensen R, Purdy AE, Fieldhouse RJ, Kimber MS, Bartlett DH, Merrill AR. 2008b. Cholix toxin, a novel ADP-ribosylating factor from Vibrio cholerae. J Biol Chem 283: 10671-10678.

Kakiuchi Y, Gális I, Tamogami S, Wabiko H. 2006. Reduction of polar auxin transport in tobacco by the tumorigenic Agrobacterium tumefaciens AK-6b gene. Planta 223: 237-247.

Kitakura S, Fujita T, Ueno Y, Terakura S, Wabiko H, Machida Y. 2002. The protein encoded by oncogene 6b from Agrobacterium tumefaciens interacts with a nuclear protein of tobacco. Plant Cell 14: 451-463.

Kitakura S, Terakura S, Yoshioka Y, Machida C, Machida Y. 2008. Interaction between Agrobacterium tumefaciens oncoprotein $6 \mathrm{~b}$ and a tobacco nucleolar protein that is homologous to TNP1 encoded by a transposable element of Antirrhinum majus. J Plant Res 121: 425-433.

Levesque H, Delepelaire P, Rouzé P, Slightom J, Tepfer D. 1988. Common evolutionary origin of the central portions of the $\mathrm{Ri}$ TL-DNA of Agrobacterium rhizogenes and the Ti TDNAs of Agrobacterium tumefaciens. Plant Mol Biol 11: 731-744.

Lobet Y, Cluff CW, Cieplak W Jr. 1991. Effect of site-directed mutagenic alterations on ADP-ribosyltransferase activity of the A subunit of Escherichia coli heat-labile enterotoxin. Infect Immun 59: 2870-2879.

O’Neal CJ, Amaya EI, Jobling MG, Holmes RK, Hol WG. 2004. Crystal structures of an intrinsically active cholera toxin mutant yield insight into the toxin activation mechanism. Biochemistry 43: 3772-3782.

O'Neal CJ, Jobling MG, Holmes RK, Hol WG. 2005. Structural basis for the activation of cholera toxin by human ARF6GTP. Science 309: 1093-1096.

Paulus F, Huss B, Tinland B, Herrmann A, Canaday J, Otten L. 1991. Role of T-region borders in Agrobacterium host range. Mol Plant Microbe Interact 4: 163-172.

Sambrook J, Fritsch EF, Maniatis T. 1989. Molecular cloning: A laboratory manual, 2nd ed. Cold Spring Harbor Laboratory Press, Cold Spring Harbor, NY.

Spena A, Schmülling T, Koncz C, Schell JS. 1987. Independent and synergistic activity of rol A, B and C loci in stimulating abnormal growth in plants. EMBO J 6: 3891-3899.

Stieger PA, Meyer AD, Kathmann P, Fründt C, Niederhauser I, Barone M, Kuhlemeier C. 2004. The orf13 T-DNA gene of Agrobacterium rhizogenes confers meristematic competence to differentiated cells. Plant Physiol 135: 1798-1808.

Terakura S, Kitakura S, Ishikawa M, Ueno Y, Fujita T, Machida C, Wabiko H, Machida Y. 2006. Oncogene 6b from Agro- bacterium tumefaciens induces abaxial cell division at late stages of leaf development and modifies vascular development in petioles. Plant Cell Physiol 47: 664-672.

Terakura S, Ueno Y, Taqami H, Kitakura S, Machida C, Wabiko H, Aiba H, Otten L, Tsukaqoshi H, Nakamura K, et al. 2007. An oncoprotein from the plant pathogen agrobacterium has histone chaperone-like activity. Plant Cell 19: 2855-2865.

Tinland B, Huss B, Paulus F, Bonnard G, Otten L. 1989. Agrobacterium tumefaciens $6 \mathrm{~b}$ genes are strain-specific and affect the activity of auxin as well as cytokinin genes. Mol Gen Genet 219: 217-224.

Tinland B, Rohfritsch O, Michler P, Otten L. 1990. Agrobacterium tumefaciens T-DNA gene $6 \mathrm{~b}$ stimulates rol-induced root formation, permits growth at high auxin concentrations and increases root size. Mol Gen Genet 223: 1-10.

Tinland B, Fournier P, Heckel T, Otten L. 1992. Expression of a chimaeric heat-shock-inducible Agrobacterium 6b oncogene in Nicotiana rustica. Plant Mol Biol 18: 921-930.

van den Akker F, Sarfaty S, Twiddy EM, Connell TD, Holmes RK, Hol HG. 1996. Crystal structure of a new heat-labile enterotoxin, LT-IIb. Structure 4: 665-678.

Wabiko H, Minemura M. 1996. Exogenous phytohormone-independent growth and regeneration of tobacco plants transgenic for the 6b gene of Agrobacterium tumefaciens AKE10. Plant Physiol 112: 939-951.

Yang J, Yuan YA. 2009. A structural perspective of the proteinRNA interactions involved in virus-induced RNA silencing and its suppression. Biochim Biophys Acta 1789: 642-652.

Yates SP, Taylor PJ, Joergensen R, Ferrraris D, Zhang J, Andersen GR, Merrill AR. 2005. Structure-function analysis of watersoluble inhibitors of the catalytic domain of exotoxin A from Pseudomonas aeruginosa. Biochem I 385: 667-675.

Zhang X, Henriques R, Lin SS, Niu QW, Chua NH. 2006a. Agrobacterium-mediated transformation of Arabidopsis thaliana using the floral dip method. Nat Protoc 1: 641-646.

Zhang X, Yuan YR, Pei Y, Lin SS, Tuschl T, Patel DJ, Chua NH. 2006b. Cucumber mosaic virus-encoded 2b suppressor inhibits Arabidopsis Argonautel cleavage activity to counter plant defense. Genes Dev 20: 3255-3268. 


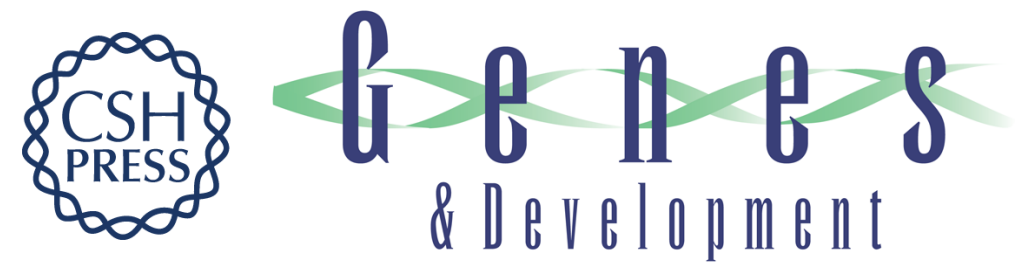

\section{Molecular insights into plant cell proliferation disturbance by Agrobacterium protein 6b}

Meimei Wang, Takashi Soyano, Satoru Machida, et al.

Genes Dev. 2011, 25: originally published online December 14, 2010

Access the most recent version at doi:10.1101/gad.1985511

\section{Supplemental http://genesdev.cshlp.org/content/suppl/2010/12/15/gad.1985511.DC1 \\ Material}

References This article cites 41 articles, 9 of which can be accessed free at:

http://genesdev.cshlp.org/content/25/1/64.full.html\#ref-list-1

\section{License}

Email Alerting

Service

Receive free email alerts when new articles cite this article - sign up in the box at the top right corner of the article or click here.

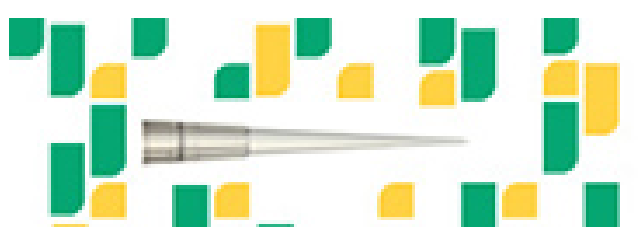

Focused on your science. 